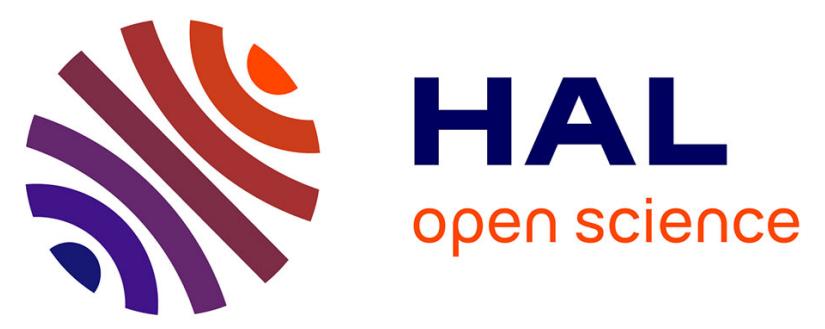

\title{
Influence of the substrate platform on the opto-electronic properties of multi-layer organic light-emitting field-effect transistors
}

Gianluca Generali, Franco Dinelli, Raffaella Capelli, Stefano Toffanin, Michele

Muccini

\section{- To cite this version:}

Gianluca Generali, Franco Dinelli, Raffaella Capelli, Stefano Toffanin, Michele Muccini. Influence of the substrate platform on the opto-electronic properties of multi-layer organic light-emitting fieldeffect transistors. Journal of Physics D: Applied Physics, 2011, 44 (22), pp.224018. 10.1088/0022$3727 / 44 / 22 / 224018$. hal-00620597

\section{HAL Id: hal-00620597 \\ https://hal.science/hal-00620597}

Submitted on 8 Sep 2011

HAL is a multi-disciplinary open access archive for the deposit and dissemination of scientific research documents, whether they are published or not. The documents may come from teaching and research institutions in France or abroad, or from public or private research centers.
L'archive ouverte pluridisciplinaire HAL, est destinée au dépôt et à la diffusion de documents scientifiques de niveau recherche, publiés ou non, émanant des établissements d'enseignement et de recherche français ou étrangers, des laboratoires publics ou privés. 


\title{
Influence of the Substrate Platform on the Opto-Electronic Properties of Multi-Layer Organic Light-Emitting Field-Effect Transistors
}

\author{
Gianluca Generali $^{1}$, Franco Dinelli ${ }^{2}$, Raffaella Capelli ${ }^{1}$, Stefano Toffanin ${ }^{1}$, Michele Muccini ${ }^{1 *}$ \\ ${ }^{1}$ Consiglio Nazionale delle Ricerche (CNR), Istituto per lo Studio dei Materiali Nanostrutturati \\ (ISMN), via P. Gobetti 101, I-40129 Bologna, Italy \\ ${ }^{2}$ Consiglio Nazionale delle Ricerche (CNR), INO U.O.S. 'A. Gozzini' Area della Ricerca di Pisa - \\ S. Cataldo, via Moruzzi 1, I-56124 Pisa, Italy
}

\begin{abstract}
In this paper, we present a study of the effects of the influence of the substrate platform on the properties of a three layer vertical hetero-junction made of thin films of $\alpha, \omega$-diperfluorohexyl-4T (DHF4T), a blend of tris(8-hydroxyquinolinato)aluminium (Alq3) and 4-(dicyanomethylene)-2methyl-6-(p-dimethylaminostyryl)-4H-pyran (DCM), and $\alpha, \omega$-dihexyl-quaterthiophene (DH4T). The hetero-junction represents the active component of an Organic Light-Emitting Transistor (OLET). The substrate platforms investigated in this study are: glass/Indium-Tin-Oxide (ITO)/Poly(methyl-methacrylate) (PMMA) and $\mathrm{Si}^{++} /$Silicon oxide $\left(\mathrm{SiO}_{2}\right) / \mathrm{PMMA}$. The first platform is almost completely transparent to light and therefore is very promising for use in OLET applications. The second one has been chosen for comparison as it employs standard microelectronic materials, i.e. $\mathrm{Si}^{++} / \mathrm{SiO}_{2}$. We show how different gate materials and structure can affect the relevant field-effect electrical characteristics, such as the charge mobility and threshold voltage. By means of an Atomic Force Microscopy analysis, a systematic study has been made in order to correlate the morphology of the active layers with the electrical properties of the devices.
\end{abstract}

\footnotetext{
*Corresponding Author Email: g.generali@bo.ismn.cnr.it, m.muccini@bo.ismn.cnr.it
} 


\section{Introduction}

Recently, organic electronics and optoelectronics has reached outstanding scientific and technological advancements. The enormous attention to plastic electronics derives from the capability to produce low-cost, large-area, lightweight and flexible devices in order to integrate functionalities currently accomplished using more expensive conventional semiconductors and components [1]. Devices such as organic light-emitting diodes (OLEDs) and organic field-effect transistors (OFETs) [2] have been widely studied and developed. A novel emerging class of optoelectronic devices is represented by Organic Light-Emitting Transistors (OLETs), which combine, in a single device, the electrical switching functionality of a field-effect transistor and the capability of light generation $[3,4]$.

In this work we report on the opto-electronic characteristics of OFET and OLET devices fabricated on two different substrate platforms: $\mathrm{Si}^{++} / \mathrm{Silicon}$ Oxide $\left(\mathrm{SiO}_{2}\right) /$ Poly(methyl-methacrylate) (PMMA) and glass/Indium-Tin-Oxide (ITO)/PMMA. The aim is to compare the effect of the two substrate platforms on the tri-layer vertical hetero-junction structure, already successfully used in OLETs as reported in an previous work of our group [5].

One of the aspects that influences the organic film formation is the interface with the dielectric, i.e. the wetting properties of the organic material. For this reasons, to study the way in which the gate material can affect the device characteristics, we have chosen two substrate platforms where the top layer is always constituted of PMMA. In this way, it is possible to exclude any interface effect that could affect the film formation and thus the device properties. $\mathrm{Si}^{++} / \mathrm{SiO}_{2}$ has been considered as it is the most commonly employed gate structure in OFETs, while ITO is more relevant for OLET applications being transparent to the emitted light. Firstly, we show data obtained on single-layer OFETs made of $\alpha, \omega$-diperfluorohexyl-quaterthiophene (DHF4T) and $\alpha, \omega$-dihexyl-quaterthiophene (DH4T). Then we present data of bi-layer vertical hetero-junction OFETs using DHF4T grown on PMMA and DH4T on top. Finally, a tri-layer OLET is fabricated by employing a blend of tris(8hydroxyquinolinato)aluminium

(Alq3) and 4-(dicyanomethylene)-2-methyl-6-( $p$ - 
dimethylaminostyryl)-4H-pyran (DCM) for the recombination layer placed in between DHF4T and DH4T. Atomic Force Microscopy (AFM) is used to analyze the morphology of the different layers of the hetero-junction grown on both substrate platforms, in order to correlate the film morphology with the opto-electronic properties of the devices.

\section{Experimental Section}

\section{Materials}

DH4T and DHF4T are employed as hole-transporting and electron-transporting layers, respectively. They are supplied by Polyera (ActivInk P0400 and ActivInk N0700) and used as received without any additional purification.

PMMA is employed as gate dielectric and is purchased by Allresist $\mathrm{GmbH}$. On $\mathrm{Si}^{++} / \mathrm{SiO}_{2}$ we have used the same PMMA used for glass/ITO susbtrates, but with diluted formulation (Allresist 176.09 on $\mathrm{Si}^{++} / \mathrm{SiO}_{2}$ and Allresist 669.06 on glass/ITO), in order to obtain the same dielectric/organic interface with a thinner film (about $1 / 4$ of PMMA thickness deposited on ITO). In this way electron trapping by $\mathrm{OH}^{-}$group at the $\mathrm{SiO}_{2}$ surface is prevented. The $\mathrm{SiO}_{2}$ layer thickness is about $300 \mathrm{~nm}$ and the overall dielectric capacity is about $10 \mathrm{nF} / \mathrm{cm}^{2}$.

The host-guest system for the recombination layer is composed by Alq3 (host) purchased from Aldrich and DCM (guest dye) purchased from Exciton.

\section{Device Fabrication}

Both the OFET devices, on glass/ITO/PMMA and $\mathrm{Si}^{++} / \mathrm{SiO} 2 / \mathrm{PMMA}$ are fabricated in a bottom gate-top contact configuration (BG-TC).

In order to prepare the substrates for device fabrication, it is crucial to perform a cleaning procedure of the substrates in order to remove any possible organic contamination. The procedures are described as follow: 
- For glass/ITO substrates, the cleaning consists in multiple exposures to acetone bath, followed by an exposure to iso-propanol bath.

- For $\mathrm{Si}^{++} / \mathrm{SiO}_{2}$ substrates, the substrate cleaning procedure consists of sequential sonication in dichloromethane, acetone, ethanol and Ultra High Pure (UHP) water.

The device fabrication procedure is the same for both substrates and consists of a deposition of a layer of PMMA [6] by spin-coating it at 6000rpm for $1 \mathrm{~min}$. under inert atmosphere. The PMMA film is then thermally annealed in a nitrogen glovebox at $\mathrm{T}=130^{\circ} \mathrm{C}$, above the $\mathrm{T}_{\mathrm{g}}$ of bulk PMMA $\left(120^{\circ} \mathrm{C}\right)$ [7]. The achieved thicknesses of PMMA are $120 \mathrm{~nm}$ on $\mathrm{Si}^{++} / \mathrm{SiO}_{2}$ substrates and $450 \mathrm{~nm}$ for glass/ITO substrates.

The active organic layers are sublimed in high vacuum at a base pressure of $10^{-6}$ mbar in a chamber directly connected to a dry nitrogen glove-box. DHF4T and DH4T are both deposited at a rate of $0.1 \AA / \mathrm{s}$ to achieve a thickness of $7 \mathrm{~nm}$ and $15 \mathrm{~nm}$, respectively. Alq3:DCM 3\% blend is co-sublimed at different rates $(2 \AA / \mathrm{s}$ for $\mathrm{Alq} 3$ and $3 \AA / \mathrm{min}$ for DCM) to form a layer thickness of $40 \mathrm{~nm}$. Gold electrodes have been evaporated at $1 \AA / \mathrm{s}$ with a thickness of $50 \mathrm{~nm}$.

The thickness of the active layers in the single layer and bi-layer devices are the same as in the trilayer configuration.

On glass/ITO substrates, the OLETs have a channel width of $70 \mu \mathrm{m}$ and a channel length of $1.5 \mathrm{~cm}$, while on $\mathrm{Si}^{++} / \mathrm{SiO} 2$ substrates they have a channel width of $150 \mu \mathrm{m}$ and a length of $1 \mathrm{~cm}$.

\section{Optoelectronic Characterization}

Electrical measurements were performed by means of a Suss PM5 professional probe station located inside a dry inert glove box and connected to an Agilent B1500A parametric analyzer. Electro-luminescence (EL) was collected through the substrate in ITO/PMMA devices and from the top side in $\mathrm{Si}^{++} / \mathrm{SiO}_{2} / \mathrm{PMMA}$ devices.

\section{Morphology Investigation}


The morphological analysis has been performed by means of a NT-MDT Solver Pro AFM working in tapping mode. The images here presented are all with a resolution of $512 \times 512$ pixels and correspond to films with the same thickness values.

\section{Results and Discussion}

To investigate, quantitatively, possible differences in terms of roughness of the two system surfaces $\left(\mathrm{Si}^{++} / \mathrm{SiO}_{2} / \mathrm{PMMA}\right.$ and ITO/PMMA), first of all an $\mathrm{AFM}$ analysis of the top layers has been performed (see Fig.1). The Root-Mean-Square (RMS) measured showed a value of $0.35 \mathrm{~nm}$ for the $\mathrm{Si}^{++} / \mathrm{SiO}_{2} / \mathrm{PMMA}$ (Fig. 1.a) and $0.5 \mathrm{~nm}$ for ITO/PMMA (Fig 1.b) surfaces. Thus the roughness parameter of the two system is very similar and it should not affect the organic film growth.

With these premises, we investigated the behaviour of the two transport materials, in a single layer OFET device, fabricated on both platforms, in order to obtain a better correlation of the effects of the different substrate platforms in a more complex device structure like the tri-layer heterojunction. In Fig.2 are shown the typical I-V curves for an OFET made with a DH4T film of $15 \mathrm{~nm}$ together with its morphology, on both platforms. The mobility value $(\mu)$, calculated from the locus curve of the OFET, on $\mathrm{Si}^{++} / \mathrm{SiO}_{2} / \mathrm{PMMA}$ is: $\mu_{\mathrm{p}}=0.04 \mathrm{~cm}^{2} / \mathrm{Vs}$, the threshold voltage $\left(\mathrm{V}_{\text {th }}\right)=-4 \mathrm{~V}$. On the ITO platform, instead, the measured values are: $\mu_{\mathrm{p}}=0.09 \mathrm{~cm}^{2} / \mathrm{Vs}$ and $\mathrm{V}_{\mathrm{th}}=-25 \mathrm{~V}$ [8]. The electrical curves (locus and transfer) in both platforms present nearly no hysteresis between the forward and backward branches. The AFM images of the two systems, show that in both platforms a very good bi-dimensional (2D) growth and crystallinity has been achieved.

On ITO/PMMA the islands growth seems slightly more isotropic compared to the $\mathrm{Si}^{++} / \mathrm{SiO}_{2} / \mathrm{PMMA}$ case. Moreover ITO/PMMA device shows a better mobility compared to $\mathrm{Si}^{++} / \mathrm{SiO}_{2} / \mathrm{PMMA}$ but a higher $\mathrm{V}_{\text {th }}$ value.

Among the many possible explanations that one could consider to interpret the observed differences in these two cases, we now briefly discuss the two most likely ones. 
In the first hypothesis, it is possible that the $\mathrm{SiO}_{2}$ layer influences the electrostatic characteristics of the PMMA surface, thus affecting the molecular organization (in terms of packing and defect density) of DH4T and making it different with respect to the DH4T film grown on ITO/PMMA.

In the second hypothesis, it might be considered that $\mu_{\mathrm{p}}$ is inversely proportional to the relative permittivity $\left(\varepsilon_{\mathrm{r}}\right),\left(\mu=\mathrm{f}\left(\varepsilon_{\mathrm{r}}^{-1}\right)\right)$, as demonstrated by Stassen et al. in the case of rubrene on dielectrics with different permittivity values [9]. In our case, indeed, the two dielectrics considered (PMMA single layer Vs. $\mathrm{SiO}_{2} / \mathrm{PMMA}$ ), have the same measured capacitance per unit area (about 10 $\mathrm{nF} / \mathrm{cm}^{2}$ ). However, since they have different internal structures and thicknesses, it results that the calculated $\varepsilon_{\mathrm{r}}$ of PMMA in single layer is 3.6 , while the $\varepsilon_{\mathrm{r}}$ of $\mathrm{SiO}_{2} / \mathrm{PMMA}$ is 5.1 (considered that this system is constituted by two capacitors in series). Finally, one effect does not exclude the other from occurring. Therefore both the effects may take place and generate the observed experimental behaviour.

In Fig. 3 are shown the electrical curves and the AFM images of a single layer OFET made of a $7 \mathrm{~nm}$ thick film of DHF4T. The calculated electrical values are: for $\mathrm{Si}^{++} / \mathrm{SiO}_{2} / \mathrm{PMMA}, \mu_{\mathrm{n}}=0.2$ $\mathrm{cm}^{2} / \mathrm{Vs}$ and $\mathrm{V}_{\mathrm{th}}=43 \mathrm{~V}$ and for ITO/PMMA, $\mu_{\mathrm{n}}=0.55 \mathrm{~cm}^{2} / \mathrm{Vs}$ and $\mathrm{V}_{\mathrm{th}}=65 \mathrm{~V}$. Also in this case, the two platforms behave in a similar way as for DH4T. ITO/PMMA presents the best results in terms of mobility, while the $\mathrm{Si}^{++} / \mathrm{SiO}_{2} / \mathrm{PMMA}$ has the lowest $\mathrm{V}_{\text {th }}$. For DHF4T, a comparison between the AFM images shows a substantial morphological difference between the two films, contrarily to what occurs for DH4T. In the ITO/PMMA case, indeed, it is present a better coverage of the substrate with larger 2D islands, while on $\mathrm{Si}^{++} / \mathrm{SiO}_{2} / \mathrm{PMMA}$ DHF4T shows the tendency to grow forming tri-dimensional crystals.

In order to have a deeper understanding of the difference in terms of DHF4T growth morphology, we also performed contact angle measurements of the underneath PMMA surfaces of the two different substrates. However, the measurements provided very similar results, with an angle of $60^{\circ}$. Most likely, there must be some microscopic effect on the surfaces that affected the growth modality of DHF4T, and that AFM analysis and contact angle measurements were unable to 
discriminate. High resolution microscopic studies will be needed in order to investigate this main issue, but this goes beyond the scope of this paper.

Before moving to the complete tri-layer device on the two platforms, we have performed another preliminary study in order to first analyze the system behaviour in a simpler structure. For this reason we have made bi-layer vertical hetero-junction OFETs as follows: $15 \mathrm{~nm}$ thick DH4T film grown on a $7 \mathrm{~nm}$ thick DHF4T layer. The electrical curves of the devices are reported in Fig. 4 . The calculated mobility and $\mathrm{V}_{\text {th }}$ values are: $\mu_{\mathrm{n}}=0.02 \mathrm{~cm}^{2} / \mathrm{Vs}, \mathrm{V}_{\mathrm{th}}=31 \mathrm{~V}$ and $\mu_{\mathrm{p}}=3 \cdot 10^{-3} \mathrm{~cm}^{2} / \mathrm{Vs}, \mathrm{V}_{\mathrm{th}}=-$ $13 \mathrm{~V}$, for $\mathrm{Si}^{++} / \mathrm{SiO}_{2} / \mathrm{PMMA} ; \mu_{\mathrm{n}}=0.01 \mathrm{~cm}^{2} / \mathrm{Vs}, \mathrm{V}_{\mathrm{th}}=40 \mathrm{~V}$ and $\mu_{\mathrm{p}}=0.01 \mathrm{~cm}^{2} / \mathrm{Vs}, \mathrm{V}_{\mathrm{th}}=-47 \mathrm{~V}$, for ITO/PMMA. In both cases, the results show a good ambipolar behaviour, in particular for ITO/PMMA, that can be considered comparable to the best results reported in the literature for ambipolar OFETs [10]. The output and transfer characteristics of the two platforms show a good balance between electrons and holes, although the best one is still on ITO/PMMA. The good ambipolarity is highlighted by the presence of the typical "V" shaped transfer curve in logarithm scale, located in the intermediate range bias.

As for single layer data, also in bi-layer OFETs $\mathrm{V}_{\text {th }}$ of $\mathrm{Si}^{++} / \mathrm{SiO}_{2} / \mathrm{PMMA}$ devices is lower than that of ITO/PMMA ones. Moreover, in both cases the electron mobility decreases considerably with respect to the single layer devices. Likely, this effect is due to a charge injection barrier formed by the presence of the DHF4T/DH4T interface.

Finally we show the data of a tri-layer vertical hetero-junction device fabricated on the two platforms and compare the different behaviours. [5]. It must be noted that, since the light detection in the $\mathrm{Si}^{++} / \mathrm{SiO}_{2} / \mathrm{PMMA}$ platform cannot be performed through the glass substrate, as instead is the case for the ITO/PMMA platform, it is possible to compare only the two EL emission behaviours and not their absolute intensities.

The electrical locus and transfer curves are reported in Fig. 5. Mobility and $V_{\text {th }}$ values of $\mathrm{Si}^{++} / \mathrm{SiO}_{2} / \mathrm{PMMA}$, calculated from the I-V curves, are: $\mu_{\mathrm{p}}=6 \cdot 10^{-5} \mathrm{~cm}^{2} / \mathrm{Vs}, \mathrm{V}_{\mathrm{th}}=-20 \mathrm{~V}$ and $\mu_{\mathrm{n}}=1 \cdot 10^{-}$ ${ }^{3} \mathrm{~cm}^{2} / \mathrm{Vs}, \mathrm{V}_{\mathrm{th}}=10 \mathrm{~V}$. Mobility and $\mathrm{V}_{\text {th }}$ voltage on ITO/PMMA platform are: $\mu_{\mathrm{p}}=5 \cdot 10^{-5} \mathrm{~cm}^{2} / \mathrm{Vs}_{\mathrm{s}}, \mathrm{V}_{\mathrm{th}}=$ 
$-40 \mathrm{~V}$ and $\mu_{\mathrm{n}}=0.5 \mathrm{~cm}^{2} / \mathrm{Vs}, \mathrm{V}_{\mathrm{th}}=34 \mathrm{~V}$. From the electrical point of view, it must be noted the poor $\mathrm{n}$ type transport on $\mathrm{Si}^{++} / \mathrm{SiO}_{2} / \mathrm{PMMA}$ compared to the one on ITO/PMMA, that is similar to that of the single layer device. The p-type mobility, instead, is very low for both systems. In both cases a large difference between the hole and electron currents is present. Finally, also in the tri-layer case, $\mathrm{Si}^{++} / \mathrm{SiO}_{2} / \mathrm{PMMA}$ shows a lower $\mathrm{V}_{\text {th }}$ for both charge carriers, compared to the ITO/PMMA counterpart.

As mentioned previously, an explanation for the lower threshold voltage on $\mathrm{Si}^{++} / \mathrm{SiO}_{2} / \mathrm{PMMA}$ might be that there is a different interaction between the gate materials of the two systems and the organic channel, enhanced by the difference in PMMA thickness [11]. When the devices are operated in the unipolar regime (Fig. 5 a-d) only one type of charge carrier is flowing in the device channel region. In both devices light emission is detected only in correspondence of the electron transport of the lower DHF4T layer. In this case, light formation is due to a diode-like mechanism that occurs when charge carriers recombine at the drain electrode. [12 -13]. When the devices are biased in the ambipolar region, thus allowing the simultaneous injection of $\mathrm{p}$ and $\mathrm{n}$-type charges, the behaviour is represented by the transfer curve (Fig. 5. e,f) in logarithm scale. In this case, contrarily to what happens in the bi-layer devices, for ITO/PMMA platform there is a very high unbalance between holes and electrons transport, and thus there is not a completely formed "V" shaped curve. Instead, on $\mathrm{Si}^{++} / \mathrm{SiO}_{2} / \mathrm{PMMA}$ platform, the two charge carriers are more balanced, although with a lower mobility with respect to the ITO/PMMA case, and thus the transfer curve has a better "V" shape characteristic.

Considering the EL emissions in ambipolar regions, it appears that in both cases there is a different light generation mechanism with respect to the unipolar case. It has been shown in the literature that in ambipolar OLETs charge recombination and the light generation process take place inside the channel far from the electrodes [14], preventing photon losses and exciton-metal quenching. On both platforms, evidence of the presence of this EL generation mechanism is represented by the higher light emission intensity in the ambipolar region of the transfer curves, compared to the 
intensity of the light emission in the unipolar locus curves, as well as a lower turn on voltage of the EL emission. Moreover, the more the two charge currents are balanced, the more the light emission peak will be located in correspondence of the maximum of ambipolarity (that corresponds to the minimum of the "V" shaped transfer curve). On $\mathrm{Si}^{++} / \mathrm{SiO}_{2} / \mathrm{PMMA}$ devices, this effect is more pronounced than on ITO/PMMA tri-layer, since electron and hole currents are more balanced and threshold voltage is lower (see Fig. 5.e).

AFM images taken on each layer of the structure for both systems are reported in Fig.6. The morphological features of the films on the two platforms are very similar except for the factthat DHF4T film deposited on ITO/PMMA forms a better 2D layer with respect to the one on $\mathrm{SiO}_{2} / \mathrm{PMMA}$. This growth difference is at the basis of the reason why n-type transport on $\mathrm{SiO}_{2} / \mathrm{PMMA}$ is so degraded. As a consequence, also the $40 \mathrm{~nm}$-thick film of Alq3:DCM grown on DHF4T on $\mathrm{SiO}_{2}$ /PMMA (shown in Fig. 6.c) has a larger 3D globular aggregation compared to ITO/PMMA (Fig. 6.d), and this affects also the growth of the 20nm-thick DH4T layer on it (Fig. 6.e), preventing a good layer-by-layer growth..

\section{Conclusions}

We reported a comparative study between OFET and OLET devices grown on two different substrate platforms, glass/ITO/PMMA and $\mathrm{Si}^{++} / \mathrm{SiO}_{2} / \mathrm{PMMA}$. We aimed at investigating the possible macroscopic effect induced on the device optoelectronic properties by different gate materials and structure. For this study we implemented a tri-layer OLET structure on two different substrate platforms.As a preliminary study, single layer and bi-layer devices have been fabricated and investigated.

From the electrical point of view, the best results in terms of mobility are obtained with the ITO/PMMA platform, while $\mathrm{Si}^{++} / \mathrm{SiO}_{2} / \mathrm{PMMA}$ devices have the lowest threshold voltages. This behaviour has been confirmed in single layer OFET made with DH4T and DHF4T and on bi-layer vertical hetero-junction OFETs made of DHF4T/DH4T. 
Then a tri-layer OLET was fabricated on $\mathrm{Si}^{++} / \mathrm{SiO}_{2} / \mathrm{PMMA}$ and its opto-electronic characteristics have been compared with those of ITO/PMMA devices. In agreement with previous results on ITO/PMMA tri-layer OLETs grown on silicon confirmed that EL emission is generated under the electrode when the device is biased in n-type unipolar region, and inside the channel when it is biased in the ambipolar regime. The p-type and n-type mobility values of $\mathrm{Si}^{++} / \mathrm{SiO}_{2} / \mathrm{PMMA}$ tri-layer OLETs are lower compared to the ITO/PMMA ones, especially for the n-type, but they are more balanced. Moreover, also in this case, the silicon tri-layer devices show lower $\mathrm{V}_{\text {th }}$ compared to the ITO/PMMA ones. From AFM analysis it results that DHF4T on $\mathrm{Si}^{++} / \mathrm{SiO}_{2} / \mathrm{PMMA}$ grows in a $3 \mathrm{D}$ fashion, unlike DHF4T on ITO/PMMA that grows in a 2D layer-by-layer modality, at least for the first few mono-layers. This also affects all the successive layers growth and is likely the main reason for the mobility on silicon to be lower. These findings confirm that a good dielectric/organic interface is necessary for achieving good opto-electronic properties, but they also highlight that other effects related to the gate materials and structure can also affect the working characteristics of the devices.

\section{Acknowledgements}

Financial support from Italian MIUR projects FIRBRBIP06YWBH (NODIS), and FIRBRBIP0642YL (LUCI), Italian MSE project Industria 2015 (ALADIN), EU projects PF6 035859-2 (BIMORE), FP7-ICT- 248052 (PHOTO-FET) and FP7-ICT- 247928 (LAMP) is acknowledged.

We thank A. Facchetti from Polyera Co. for supplying DH4T and DFH4T. 


\section{References}

[1] S. R. Forrest, Nature. 428 (2004) 911-918.

[2] D. J. Gundlach, Y. Y. Lin, T. N. Jackson, S. F. Nelson, D. G. Schlom, IEEE Electron. Dev. Lett. 18 (1997) 87-89.

[3] M. Muccini, Nat. Mater. 5 (2006) 605-613.

[4] C. Rost, et al, Appl. Phys. Lett. 85 (2004) 1613-1615.

[5] R. Capelli, et al. (2010). Nat. Mater. 9, 6 (2010) 496-503.

[6] F. Todescato; R. Capelli; F. Dinelli; M. Murgia; N. Camaioni; M. Yang; R. Bozio; M. Muccini, J. Phys. Chem. B 112 (2008) 10130.

[7] J. Brandrup; E. H. Immergut, Polymer Handbook, third ed., Wiley, New York, (1989).

[8] G. Generali; R. Capelli; S. Toffanin; A. Facchetti; M. Muccini Microelectron. Reliab. 50, 9-11 (2010) 1861.

[9] A. F. Stassen, R. W. I. de Boer, N. N. Iosad, and A. F. Morpurgo, App. Phys. Lett. 85, 17 (2004) 3899-3901.

[10] R. Ye, M. Baba, K. Ohta, K. Kazunori Suzuki, K. Mori, Jap. J. Appl. Phys. 48, (2009) 04C1681-04C1683.

[11] J.-H.Kwonet al. Microelectron.Eng. 87 (2010) 2306-2311

[12] A. Hepp, et al, Phys. Rev. Lett. 91 (2003) 1574061-1574064.

[13] E. B. Namdas, P. Ledochowitsch, J. D. Yuen, D. Moses, A. J. Heeger. Appl. Phys. Lett. 92 (2008) 183304.

[14] J. Zaumseil, R. H. Friend, H. Sirringhaus. (2006). Nat. Mater. 5, 1 (2006) 69-74. 

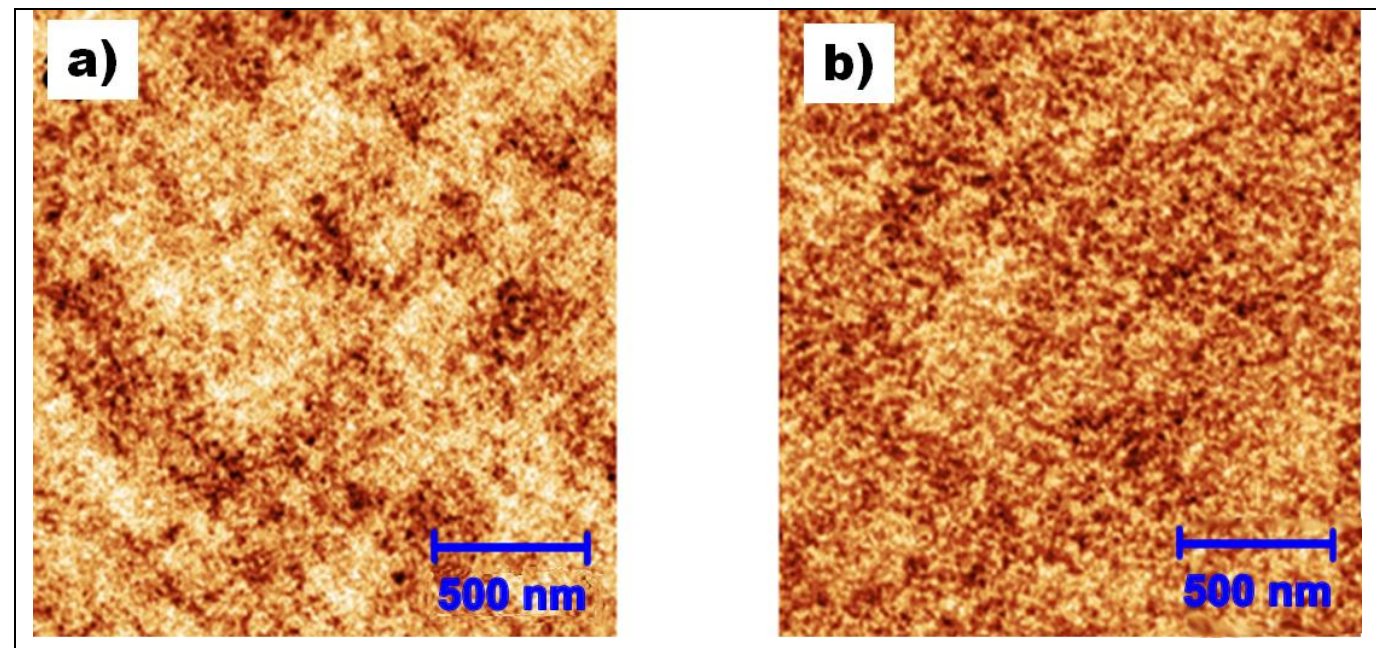

Fig. 1. AFM images of the PMMA on $\mathrm{SiO}_{2}$ surface (a) and PMMA on ITO surface (b).

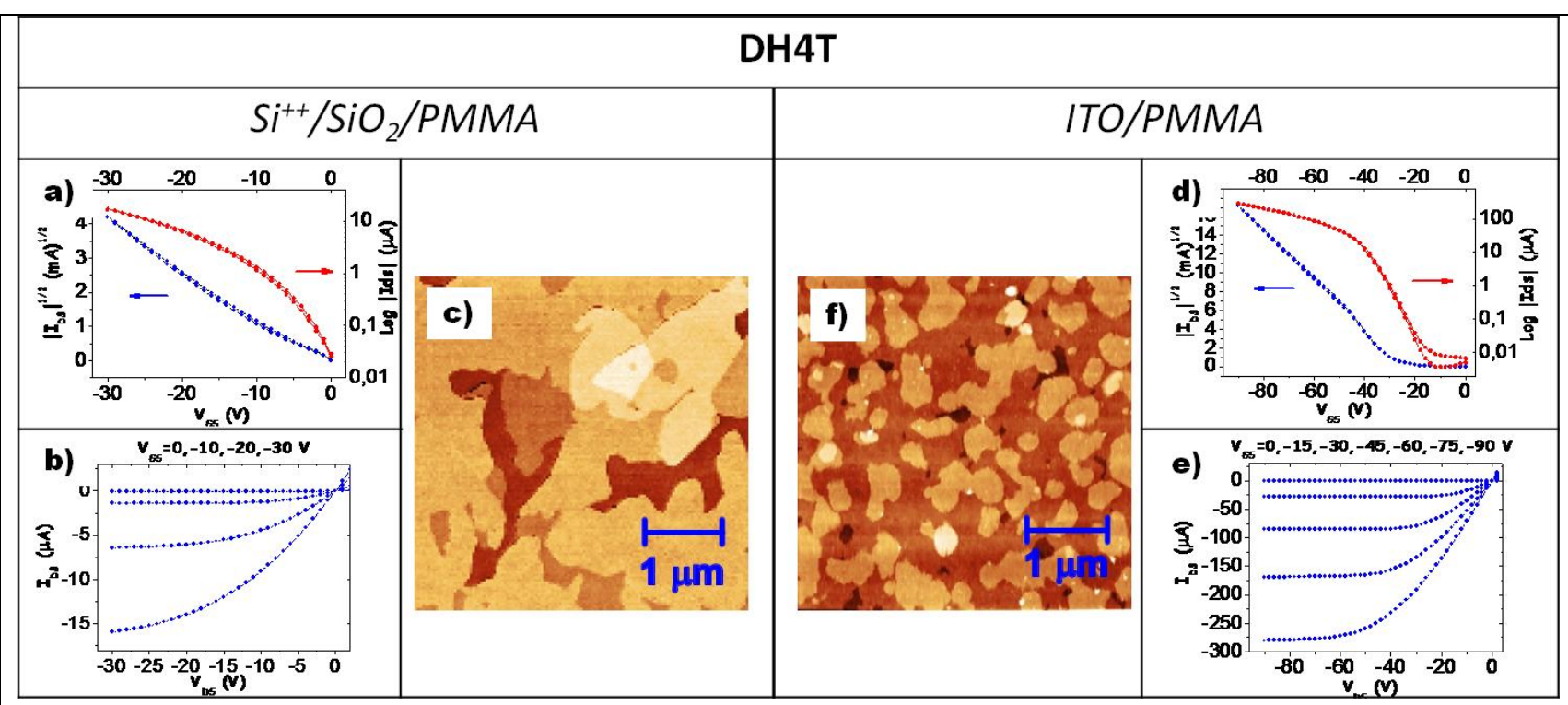

Fig. 2. Comparison between electrical characteristics and morphological features of DH4T single layer OFET on $\mathrm{Si}^{++} / \mathrm{SiO}_{2} / \mathrm{PMMA}$ substrate (left side) and on glass/ITO/PMMA substrate (right side). The electrical curves of both sides represent, respectively: the I-V output curve $(b, e)$, the square root of Locus Curve (blue dots of a and $d$, left $Y$-axis), the Transfer curve in saturation regime (red dots of a and $d$, right $\mathrm{Y}$-axis expressed in logarithm scale). 

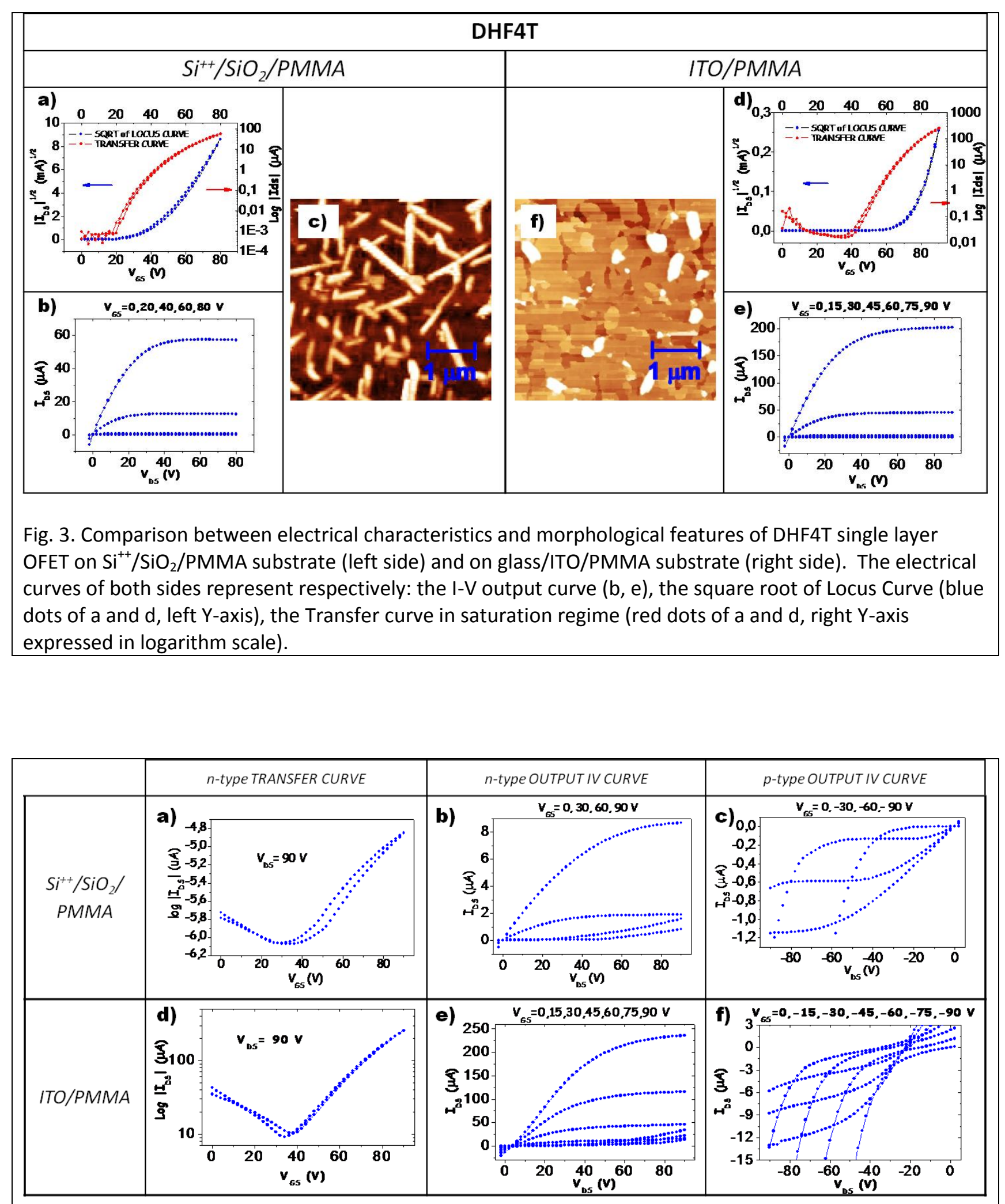

Fig. 4. Electrical curves of a bi-layer OFET of DHF4T/DH4T on $\mathrm{Si}^{++} / \mathrm{SiO}_{2} / \mathrm{PMMA}$ (upper row) and on glass/ITO/PMMA substrates (lower row). 


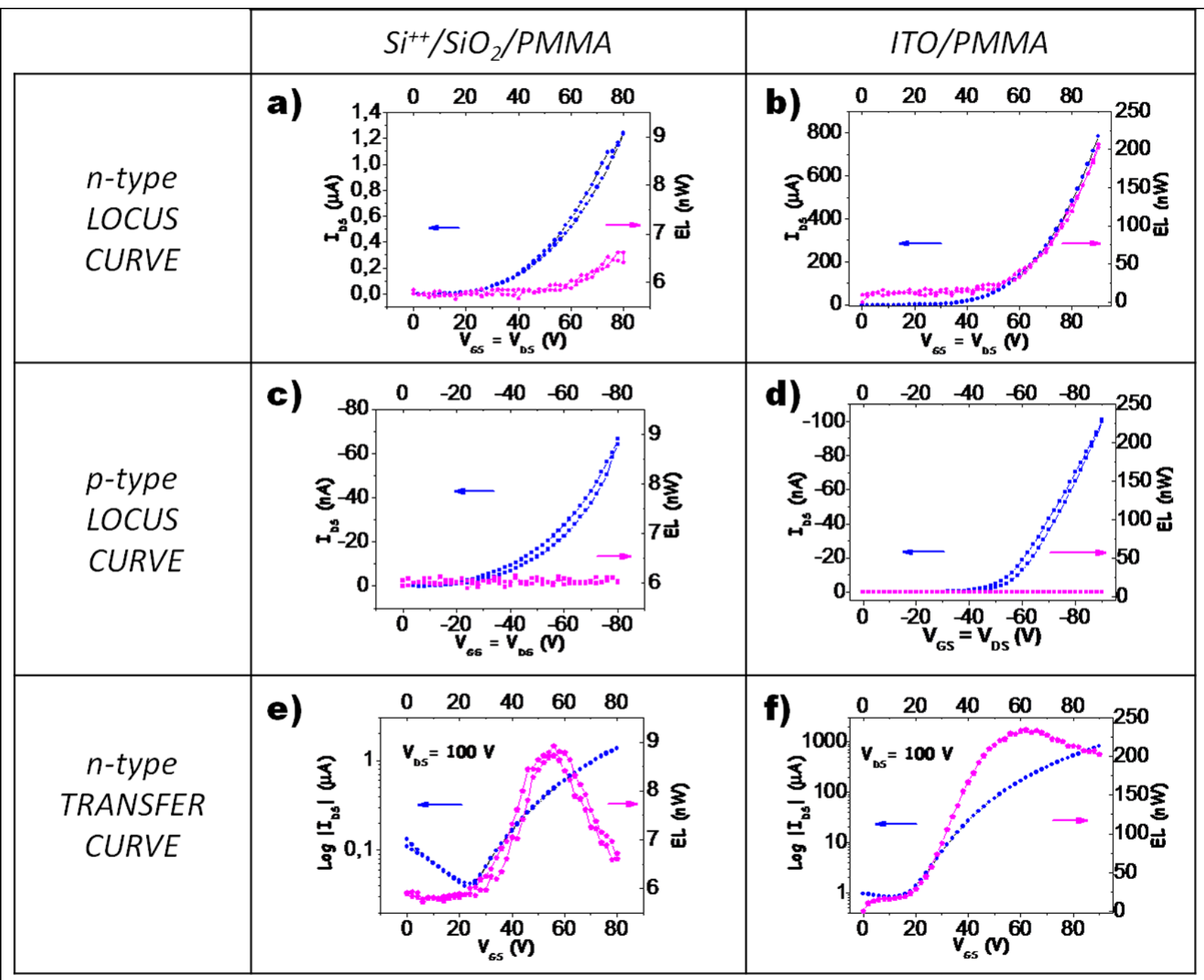

Fig. 5. Electrical curves of tri-layer OLETs on $\mathrm{Si}^{++} / \mathrm{SiO}_{2} / \mathrm{PMMA}$ (left column) and on ITO/PMMA (right column). The blue dots represent the drain-source current while the purple dots represent the electroluminescence intensity. 


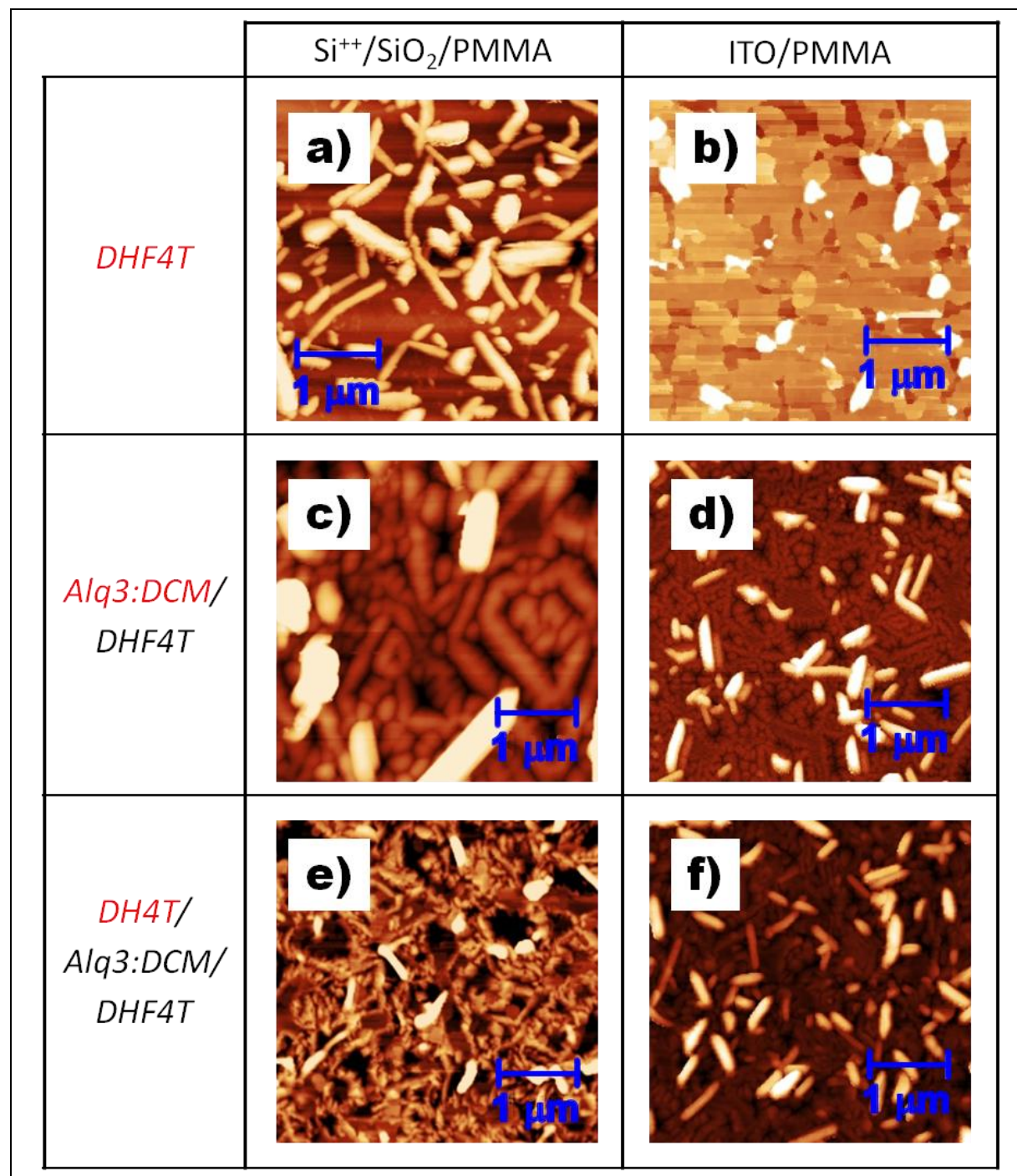

Fig. 6. AFM pictures of organic layers of the tri-layer OLET on $\mathrm{SiO}_{2} / \mathrm{PMMA}$ (left column) and on ITO/PMMA (right column) substrates. The material name, highlighted in red (left column), refers to the images of the same row.

$(a, b) 7 \mathrm{~nm}$-thick DHF4T layer on top of the two different substrates. (c,d) Images of a 40-nm-thick film of Alq3:DCM (3\%) blend on top of DHF4T layer, and (e,f) DH4T films grown on top of the Alq3:DCM (3\%) layers reported in (c, d). 